\title{
Application of SPOCs under Theory of Multiple Intelligences
}

\author{
Chunying Zhang ${ }^{1, a^{*}}$ and Weihong Zhang ${ }^{2, b}$ \\ ${ }^{1}$ Department of Foreign Languages and Cultures, Beijing Wuzi University,Beijing, China \\ ${ }^{2}$ English Department, Hebei Tourism Vocational College, Chengde City, China \\ azhangchunying1979@sina.com, ${ }^{\mathrm{b}}$ mayzhwh@126.com
}

Keywords: Small private open online course; Higher education; Multiple intelligences; Foreign language teaching and learning; Curriculum reform

\begin{abstract}
The main focus of present study is to explore a new teaching model which is adapted to the development of the modern society. This study describes the features of SPOCs and the Theory of Multiple Intelligences and outlines some of the benefits that SPOCs bring to the foreign language teaching and learning in Chinese higher education. This study clearly points out that teachers need to have the educational concept of multiple intelligences and develop multiple intelligences in SPOC era in order to guarantee diversified development of students and ignite students' curiosity and interest in learning foreign languages. This paper also shows the scoring criteria for making SPOC videos and gives the brief notes that teachers should pay attention to when recording SPOCs. We confirmed that SPOCs can facilitate students' learning of the foreign languages, enhancing the learning process immensely and at the same time they can extend and deepen teachers' professional learning.
\end{abstract}

\section{Introduction}

New changes have appeared in higher education since 2012. Firstly, Massive Open Online Courses (MOOCs, for short) impact on the global higher education like tsunami and avalanche [1], accelerating the process of the integration of higher education. Secondly, the use of Small Private Open Online Courses (SPOCs, for short) has offered a better online teaching model that has won the acceptance of university education [2].

Dave Cormier and Bryan Alexander coined the term MOOC in 2008. The New York Times dubbed 2012 "The Year of the MOOC." [3]MOOCs online education noticeably affected higher education around the world. But the greatest problem is how tens of thousands of students on a course could ever satisfactorily be taught, assessed and accredited. Most of these signs-up will sign off without completing courses. At present, there appears the move towards more flexible and refined formats such as SPOCs as an "almost inevitable evolution". Professor Lue says "The MOOC represents just the first version of what we can do with online education." And this first version has now been overtaken. "We're already in a post-MOOC era. [4]"

SPOC was proposed by Professor Armando Fox from University of California at Berkeley in the United States in 2013. SPOC platform is mainly for on-campus students, enabling a four-fold increase in student intake, providing more learner practice, redirecting teaching assistants' attention from grading to higher-value forms of feedback, and ultimately increasing course ratings. Therefore, SPOC platform is called as "the textbook of the next generation. [5]" SPOCs are small, and studied by tens or hundreds. SPOCs are usually resourced based on the number of enrolments. SPOCs achieve this through competitive application processes for limited places.

\section{Understanding and Practice of SPOCs in China}

"Phoenix SPOCs" are the earliest SPOCs in China. "Phoenix SPOCs" was jointly launched by South China Normal University and Phoenix Satellite TV at the end of December 2012. The SPOCs lasted only five to ten minutes. Some of them even lasted shorter than five minutes. The SPOCs base on the 
micro video as the main carrier, particularly suitable for smart phones, tablet personal computers and other mobile devices. It is very convenient for people to study through these devices.

"Phoenix SPOCs" have been released to the world currently and they are available to Microsoft Window 8 and apple's version of iOS now. Developing and promoting new applications for mobile learning is mainly to satisfy people's learning needs in today's fast paced lifestyle and can get better results because it is very convenient for people to study anywhere through mobile phones or laptops, for example, in the school, on the road, in the park or on the bus.

$\mathrm{Hu}$ Tiesheng, the famous SPOCs practice researcher, is a teacher of the education information center in Foshan city. According to his opinion, the SPOC is the organic combination of a variety of teaching resources that are used to develop teaching and learning activities. It's based on the requirements of the new curriculum standard and teaching practice and takes the teaching video as the main carrier. Teachers only explain some knowledge point in the videos. The core content of SPOCs consists of classroom teaching videos and teaching support materials such as teaching designs, courseware materials, teaching reflection and practice test, student feedback and teacher commenting.

Li Jiahou is a lecturer of the Shanghai Normal University. In his view, when making micro-videos, teachers should combine the learning task and students' learning activities together. If no students take part in the teaching and learning activity and only the teacher records a class teaching activity, the video is just a recording of class teaching activity essentially. It can be used as the learning materials, but it doesn't form the SPOC system. From the perspective of general education resource, the SPOC is an innovation on the learning resource in the process of the curriculum reform and the informationization and it's also a new type of resource that integrate the learning content with the learning method. Some teachers generalize the SPOC into "a digital learning resource package with the features of contextualization, interestingness and visualization."

According to Ten-year Development Plan for Education Informatization (2011-2020)[6], college teachers should solve the problems that have appeared in the process of the reform and development of education and promote the innovation of education, teaching and management by taking the advantage of building and sharing high quality digital education resources and in-depth integration of information technology with education. With the advent of the era of education informatization, there will appear much more abundant network "micro" products in the traditional teaching domain in the near future. Although classroom teaching may still be the main way for students to acquire knowledge, we should pay attention to the shock to the traditional classroom teaching, for example, teaching designs, learning methods, the organization mode, the relationship between teachers and students.

SPOCs in the Application of Foreign Language Teaching in Colleges and Universities. In order to adapt to the development of the times and change the current foreign language teaching situation in Chinese colleges and universities, we must improve teachers' teaching abilities and stimulate students' interest in learning foreign languages. If SPOCs, the advanced teaching method, are applied in classroom teaching, it can bring great benefits to the foreign language teaching.

Application of SPOCs in Classroom Teaching. Firstly, SPOCs can facilitate students' review after class. Teachers can make review videos in accordance with the teaching requirements and students' actual situation so that students can consolidate their knowledge by watching the videos. Both vocabulary and grammar can be detected by this method so that the students can review what they have learned. Secondly, SPOCs can be used in the teachers' introduction of the new lesson. Teachers can make nice videos according to the teaching content which can attract students at the beginning of the class. Finally, SPOCs can also help teachers highlight the key points and difficulties in the teaching process. If the teacher shows and explains the teaching content through the video, it's much easier for the students to understand and master the new knowledge. Besides, teachers can make some extended videos for students to watch after class and add some related knowledge and exercises to expand students' knowledge and improve students' comprehensive ability at the same time.

Application of SPOCs in Autonomous Learning. Due to the development of the modern network and the popularity of computers, autonomous learning has become possible for the students at college. The SPOC as a kind of online video is welcomed by students because online learning is the 
most convenient and flexible way to learn. It's not necessarily subject to the restrictions of space and time and no longer just faces dull tedious learning materials, which can enhance students' learning autonomy. Furthermore, the SPOC is suitable for students at all levels to learn. Because the English level of students is uneven, some problems that are difficult to solve in the original classroom teaching can be solved through the SPOC. Online videos can be played repeatedly. Students can select suitable learning methods and learning materials according to their various levels until it is mastered. Thus, it is much more advantageous for students to study autonomously.

Application of SPOCs Can Promote Teachers' Development. When teachers prepare SPOC videos and modify them they can find the problems that exist in the teaching process and timely analyze and solve the problems and improve their professional ability through constant reflection and continuous improvement. Meanwhile, when teachers make SPOC videos they need to use the knowledge of the network, computer, recording, editing, etc. which helps to improve teachers' capabilities to use information technology. The SPOC is an irresistible wave of momentum entering the university foreign language classroom. In order to cultivate more excellent compound talents, foreign language teachers should build a platform combining the online learning lecture hall with the real school learning classroom so that students can learn far more easily and independently, thus improving their foreign language level and realizing the teaching optimization.

\section{Need for Teachers' Ongoing Professional Development of Multiple Intelligences in the SPOC Era}

How to design and utilize SPOCs is a challenge to traditional teaching methods, teachers' ideas, teachers' knowledge, teachers' capabilities and teachers' role. The ultimate goal of SPOCs is to realize the personalized development of students through student-centered instruction. The personalized development of students is also called diversified development. To guarantee diversified development of students, teachers must know the theory of multiple intelligences and have the educational concept of multiple intelligences and use multiple intelligence teaching methods.

Dr. Howard Gardner, a psychologist and professor of education at Harvard University, developed a theory called "Multiple Intelligences" in 1983. This theory is put forward through studying pedagogy, psychology, physiology, behavior and the analysis of large amounts of data. Gardner articulated eight criteria for a behavior to be considered an intelligence[7]. These were that the intelligences showed: potential for brain isolation by brain damage, place in evolutionary history, presence of core operations, susceptibility to encoding (symbolic expression), a distinct developmental progression, the existence of savants, prodigies and other exceptional people, and support from experimental psychology and psychometric findings. Gardner chose eight abilities that he held to meet these criteria[8]: musical-rhythmic, visual-spatial, verbal-linguistic, logical-mathematical, bodily-kinesthetic, interpersonal, intrapersonal, and naturalistic[9]. Gardner opposes the idea of labeling learners to a specific intelligence. He held that everybody has a different mind, and no two profiles of intelligence are the same. From the 8 primary intelligences, an individual may excel in one, two or even three of these, but nobody's good at them all[10].

Teachers Should Master Educational Concept of Multiple Intelligences. To stimulate students' multiple intelligences, teachers must master the theory and ideas of multiple intelligences. According to the characteristics and requirements of SPOCs, teachers should grasp the following educational concepts of multiple intelligences.

The first is the concept of student under the theory of multiple intelligences. It's sure that each student possesses a unique blend of all the intelligences and may have a particular strength. No matter which kind of special advantages, it has the value of life. Teachers should respect the uniqueness and differences of each student's intelligence.

The second is the concept of objective under the theory of multiple intelligences. One of the immediate aims of teaching activities is to make students really understand what they have learned and can be flexible in using them, which requires teachers to put emphasis on the cultivation of 
students' multiple intelligences, namely the idea of "teaching for understanding". Therefore, SPOCs should be designed to guide and help students to actually understand and flexibly apply each knowledge point.

The third is the concept of teaching under the theory of multiple intelligences. To bring into full play each student's intellectual strength, teachers should take full advantage of their own multiple intelligences or the team's multiple intelligences, designing the teaching mode that can stimulate students' multiple intelligence to promote the development of students' multiple intelligences.

The fourth is the concept of evaluation under the theory of multiple intelligences. The Theory of Multiple Intelligences suggests that teachers assess the progress of individual students from a developmental perspective and establish a student assessment inventory of learning process that actually is a materials collecting sheet designedly and systematically recording and reflecting each student's efforts, progress and achievements in a longer period of time. It can make teachers have a comprehensive understanding of the real performances of each student in the teaching process and it also can provide teachers and parents with the basis of students' self-awareness, learning practice, interpersonal communication and psychological development. Meanwhile, it can give students the chance of self-reflection and self-assessment by reviewing their own learning diaries or projects.

Teachers' Development of Multiple Intelligences. Firstly, teachers should develop verbal-linguistic intelligence. When teachers make SPOC videos, they should use the concise and precise words. When they are teaching, they should use the language of enlightenment. Secondly, teachers should develop logical-mathematical intelligence. In the process of making SPOC videos, teachers should be good at finding and refining the key points of knowledge. Thirdly, teachers should develop visual-spatial intelligence. In the process of making SPOC videos and classroom teaching, teachers should show and explain the new knowledge in the form of images, charts, or diagrams guiding and enlightening students to learn intuitively. Besides, teachers should have the right attitude towards their own knowledge and abilities and continuously promote self-development to achieve a new level of self-awareness.

\section{Summary}

The SPOC can be used as a powerful supplement of the traditional foreign language teaching and learning to promote foreign language teaching in colleges and universities. National quality education is consistent with the diversity teaching theory of multiple intelligences which provides a new research direction for the reform of college foreign language teaching. College foreign language teachers should take the initiative to establish the education concept of multiple intelligences and try to tap and develop their potentials of multiple intelligences by training or self-study so that they can design, develop and implement SPOCs better and integrate SPOCs with traditional foreign language teaching methods to improve the quality of college foreign language teaching comprehensively.

\section{References}

[1] Vernon J., Open online courses-an avalanche that might just get stopped [N], The Guardian, April 30, 2013.

[2] Yang Yong-lin, Zhang Shi-rong, Ding Tao, Zhang Hong, Wang Na. Using Big Data in the Teaching of English Writing in the MOOC and SPOC Era[A].Modern Educational Technology.Beijing.Vol.24 no. 12, 2014, p 45-5.

[3] Information

on

http://

theweek.com/articles/563541/are-small-private-online-courses-future-higher-education-america

[4] Information on http://www.bbc.com/news/business-24166247. 
[5] Wu Chan, Thinking on the Optimization of Micro-lesson to College Teaching Effect[A], Higher Education Forum, The Guide of Science \& Education, Hubei Province, October, 2013.

[6] Wei Shunping, On the Full-scale and In-depth Integration of ICT and Distance Education[J], Journal of Hebei Radio and TV University, 2013-01.

[7] Gilman, Lynn, The Theory of Multiple Intelligences, Indiana University, Retrieved 14 November 2012.

[8] Slavin, Robert, Educational Psychology, p. 117, ISBN 0-205-59200-7.

[9] Information on https://en.wikipedia.org/wiki/Theory_of_multiple_intelligences.

[10] Information on http://www.multipleintelligencetheory.co.uk. 